\title{
Refractive errors in patients with fundus flavimaculatus
}

\author{
DAVID. S. DOKA, ' GERALD A. FISHMAN, ' AND ROBERT J. ANDERSON ${ }^{2}$ \\ From the ${ }^{1}$ Department of Ophthalmology, University of Illinois Hospital Eye and Ear Infirmary, \\ and the ${ }^{2}$ Epidemiology and Biometry Program, School of Public Health, University of Illinois at the \\ Medical Center, Chicago, USA
}

SUMMARY A total of 59 patients (118 eyes) with fundus flavimaculatus who had atrophic macular lesions were examined for refractive error. Myopic refractions of greater than $-0 \cdot 1$ dioptre were seen in $12 \%$ of a normal population and in $76 \%$ of our patient population. The spherical equivalent refractive errors described a single-peaked skewed distribution with a mean of $-1 \cdot 12$ dioptres, which is $2 \cdot 12$ dioptres more myopic than that of a normal population. In addition astigmatic refractive errors of greater than +0.5 dioptres were found in $42 \%$ of this patient population, which is considerably more than the $18.6 \%$ observed in a normal population.

It has been previously recognised that an increased incidence of myopic and astigmatic refractive errors is present in certain heritable chorioretinal diseases. In a study of patients with congenital stationary night blindness with clinically normal fundi Carr found 13 of 14 patients to be myopic, with spherical equivalent refractive errors ranging from $-2 \cdot 00$ to $-14 \cdot 00$ dioptres (mean, $-6 \cdot 00$ dioptres). ${ }^{\prime}$ In a study of 134 retinitis pigmentosa patients Sieving and Fishman found a predominance of myopic refractive errors. ${ }^{2}$ In their group the mean spherical refractive error was -1.86 dioptres, which is 2.96 dioptres more myopic than the normal mean of +1.00 dioptre. $^{3}$ Furthermore $74 \%$ of these retinitis pigmentosa patients had astigmatic errors greater than +0.5 dioptre $^{2}$ as compared with only $19 \%$ of a normal population. ${ }^{3}$ Krill noted that 80 to $90 \%$ of patients with gyrate atrophy of the choroid and retina have myopia to variable degrees. ${ }^{4} \mathrm{~A}$ similar increase in myopic and astigmatic refractive errors seemed to be present in patients with fundus flavimaculatus. To confirm this supposition we undertook a study of refractive errors in 59 patients with fundus flavimaculatus with associated atrophic macular lesions.

Correspondence to G. A. Fishman, MD, University of Illinois Eye and Ear Infirmary, 1855 West Taylor Street. Chicago, Illinois 60612 , USA.

\section{Patients and methods}

Our study population consisted of 59 patients (118 eyes) with fundus flavimaculatus. All patients had an atrophic-like foveal lesion with either a ring or a more extensive garland of flecks within the posterior pole that extended to the equator in some instances. These cases have previously been described as stage I and stage II fundus flavimaculatus, respectively, by Fishman. ${ }^{5}$ Patients with stage I and stage II fundus flavimaculatus without atrophic macular lesions were not included. Also excluded were patients with more extensive retinal pigment epithelial or choriocapillaris disease, described as stage III and stage IV fundus flavimaculatus, respectively, by Fishman. ${ }^{5}$ In the latter group of patients there is more widespread atrophy of the retinal pigment epithelium and choriocapillaris, with extensive reabsorption of flecks, which makes the diagnosis of fundus flavimaculatus less apparent.

All refractive errors were obtained by manifest refraction. The majority were performed by one of the authors (D.D.); refractions from 3 patients were previously obtained by other physicians. The spherical refractive errors were calculated algebraically by adding one-half of the cylindrical correction to the spherical correction. Cylindrical refractive errors were measured and analysed in positive dioptres. None of the patients was aphakic.

Data on the refractive errors in the general 


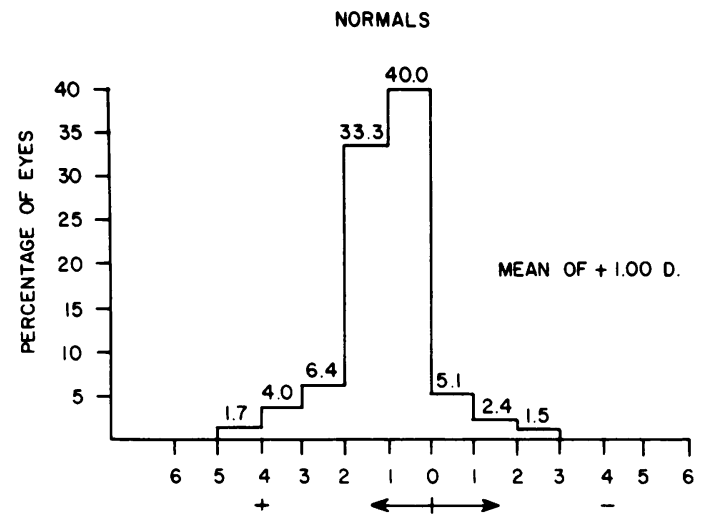

SPHERICAL EQUIVALENT REFRACTIVE ERRORS (DIOPTERS)

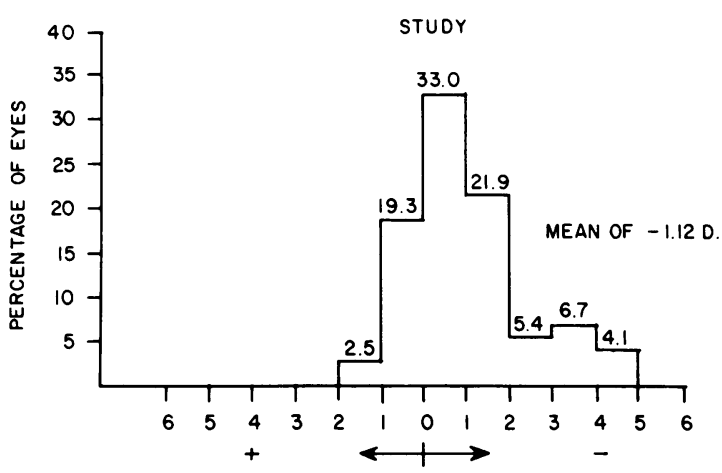

SPHERICAL EQUIVALENT REFRACTIVE ERRORS (DIOPTERS)

Fig. 1 Spherical equivalent refractive errors from normal population compared with those of our fundus flavimaculatus patients.

population were taken from a study by Sorsby et al. ${ }^{3}$ who sampled 1033 male National Service recruits in Great Britain in 1957 (aged 17 to 27 years). These authors included in their study a weighted addition of cases selected at random from a pool of men rejected from service because of high refractive errors. This study approaches an unbiased series of the general male population. A similar well controlled and unbiased series of the female population is unavailable.

\section{Results}

The spherical equivalent refractive errors for the 118 eyes studied ranged from $+4 \cdot 50$ dioptres to $-7 \cdot 25$ dioptres. The mean refractive error is 2.12 dioptres more myopic than the mean spherical equivalent
Table 1 Percentage distribution of spherical equivalent in study population $(n=59)$

\begin{tabular}{llll}
\hline $\begin{array}{l}\text { Spherical equivalent } \\
(D)\end{array}$ & $O D, \%$ & $O S, \%$ & Best eve, \% \\
\hline$-8 \cdot 0$ to $-7 \cdot 1$ & $1 \cdot 7$ & $1 \cdot 7$ & $1 \cdot 7$ \\
$-7 \cdot 0$ to $-6 \cdot 1$ & 0 & 0 & 0 \\
$-6 \cdot 0$ to $-5 \cdot 1$ & 0 & 0 & 0 \\
$-5 \cdot 0$ to $-4 \cdot 1$ & $3 \cdot 4$ & $5 \cdot 1$ & $5 \cdot 1$ \\
$-4 \cdot 0$ to $-3 \cdot 1$ & $6 \cdot 8$ & $6 \cdot 8$ & $8 \cdot 5$ \\
$-3 \cdot 0$ to $-2 \cdot 1$ & $11 \cdot 9$ & $3 \cdot 4$ & $8 \cdot 5$ \\
$-2 \cdot 0$ to $-1 \cdot 1$ & $25 \cdot 4$ & $22 \cdot 0$ & $25 \cdot 4$ \\
$-1 \cdot 0$ to $-0 \cdot 1$ & $27 \cdot 1$ & $32 \cdot 2$ & $28 \cdot 8$ \\
0 to $+0 \cdot 9$ & $18 \cdot 6$ & $22 \cdot 0$ & $18 \cdot 6$ \\
$+1 \cdot 0$ to $+1 \cdot 9$ & $3 \cdot 4$ & $5 \cdot 1$ & $1 \cdot 7$ \\
$+2 \cdot 0$ to $+2 \cdot 9$ & 0 & 0 & 0 \\
$+3 \cdot 0$ to $+3 \cdot 9$ & $1 \cdot 7$ & 0 & $1 \cdot 7$ \\
$+4 \cdot 0$ to $+4 \cdot 9$ & 0 & $1 \cdot 7$ & 0 \\
\hline
\end{tabular}

refractive error of a normal population (Fig. 1). Myopic refractions of greater than $-0 \cdot 1$ dioptre were seen in $12 \%$ of a normal population ${ }^{3}$ and in $76 \%$ of our population. In addition there is a skew to the higher myopic refractive errors within the patient population. When the study group was subdivided into right, left, and best eyes (Table 1), a similar distribution was obtained. There was no statistical difference in the distribution of refractive errors between males and females. Furthermore there was no positive correlation between age and refractive error.

This study population also showed an increased incidence of cylindrical refractive errors. Cylindrical errors greater than +0.5 dioptre were found in $42 \%$ of the study population as compared with $19 \%$ of a normal population.

\section{Discussion}

Our analysis of refractive errors in patients with stage I and stage II fundus flavimaculatus with associated atrophic macular lesions showed a significant myopic shift of the mean spherical equivalent refractive error and a greater prevalence of astigmatic refractive errors, as compared with a normal population compiled by Sorsby $e t$ al. ${ }^{3}$

We note that Sorsby and coworkers derived their 'normal distribution' differently from that used for our fundus flavimaculatus population. For the $81 \%$ of their population who had cylinders less than or equal to +0.5 dioptre they used the same 'spherical equivalent' method as in our population. For the remaining $19 \%$ of their population, who had cylinders greater than +0.5 dioptre, they used the least ametropic meridian, a technique that understates the true spherical refractive error of the eye. Sorsby et al. found that astigmatic values greater than +0.5 dioptre were concentrated round the central spherical 
values and were proportionally more frequent with hypermetropic than myopic refractions. Thus, if their spherical errors were converted entirely to spherical equivalent values, the mean of their data would be slightly more hypermetropic than is presented here.

The significance as well as the explanation of our findings remain uncertain. Rabin and coworkers ${ }^{6}$ have suggested from retrospective studies that an alteration in visual experience that disrupts pattern vision early in life, such as that which occurs in macular dystrophies, may result in a form of deprivationinduced myopia. Whether abnormalities in the cornea, lens, depth of the anterior chamber, or axial length of the globe singularly or combined are aetiological factors is yet to be determined. Such features are now being investigated in this population.

Morton F. Goldberg. MD, and Maxine Gere reviewed the manuscript: Juanita Waddy typed the manuscript.

This investigation was supported in part by core grant
1P30EYO1792 and grant EY-703802 from the National Eve Institute. National Institutes of Health, Bethesda, Maryland; by an unrestricted grant and Manpower award from Research to Prevent Blindness, Inc., NYC, and by a research grant from the National Retinitis Pigmentosa Foundation, Baltimore, Maryland.

\section{References}

1 Carr RE. Congenital stationary nightblindness. Trans Am Ophthalmol Soc 1974; 72: 448-7.

2 Sieving PA. Fishman, GA. Refractive errors of retinitis pigmentosa patients. Br J Ophthalmol 1978; 62: 163-7.

3 Sorsby A. Sheridan M. Leary GA. et al. Vision, visual acuity, and ocular refraction of young men. $\mathrm{Br}$ Med J 1960; i: 1394-8.

4 Krill AE. Diffuse total choroidal vascular atrophy of autosomal inheritance (gyrate atrophy of the choroid and retina: Fuchs's gyrate atrophy). In: Krill's Hereditary Retinal and Choroidal Diseases. Hagerstown. Harper and Row, 1977: 1010.

5 Fishman GA. Fundus flavimaculatus. Arch Ophthalmol 1976; 94: 2061-7.

6 Rabin J. Van Sluyters RC. Malach R. Emmetropization: a visiondependent phenomenon. Invest Ophthalmol Visual Sci 1981; 20: 561-4. 